Revista Brasileira de Meteorologia, v.28, n.3, 291 - 304, 2013

\title{
IMPACTO DA TEMPERATURA DA SUPERFÍCIE DO MAR NA SIMULAÇÃO DA ZONA DE CONVERGÊNCIA DO ATLÂNTICO SUL
}

\author{
ANA CAROLINA NÓBILE TOMAZIELLO, ADILSON WAGNER GANDU
}

\author{
Universidade de São Paulo, Instituto de Astronomia, Geofísica e Ciências Atmosféricas, Departamento de \\ Ciências Atmosféricas, São Paulo, SP, Brasil \\ carolnobile@model.iag.usp.br, adwgandu@model.iag.usp.br
}

Recebido Julho de 2012 - Aceito Março de 2013

\begin{abstract}
RESUMO
Durante o verão austral, diversas regiões do Brasil são afetadas por precipitação intensa, geralmente associada à Zona de Convergência do Atlântico Sul (ZCAS). O objetivo geral deste trabalho foi investigar a influência da resolução espacial e temporal dos dados de temperatura da superfície do mar (TSM) na simulação da precipitação associada à ZCAS. Foram realizadas simulações com o modelo BRAMS (Brazilian developments on the Regional Atmospheric Modeling System) para dois eventos de ZCAS, ocorridos em 1998 (El Niño) e 1999 (La Niña). A quantidade de precipitação acumulada na parte oceânica da ZCAS foi maior nos experimentos com TSM mais quente. Índices estatísticos foram utilizados para verificação do desempenho do modelo na simulação de precipitação nas regiões que compõem a ZCAS (oceânica, costeira e amazônica), com diferentes dados de TSM. A resolução espaço-temporal dos dados de TSM influencia de forma pouco significativa na representação da ZCAS pelo modelo BRAMS. O modelo é mais eficiente em identificar a ocorrência/não ocorrência de chuva do que em localizar núcleos mais intensos e seu desempenho foi superior (inferior) na região amazônica (oceânica) da ZCAS.
\end{abstract}

Palavras-chave: modelagem numérica, ZCAS, TSM, precipitação.

\begin{abstract}
IMPACT OF SEA SURFACE TEMPERATURE IN THE SIMULATION OF SOUTH ATLANTIC CONVERGENCE ZONE

During austral summer, several regions of Brazil are affected by intense precipitation, generally associated with the South Atlantic Convergence Zone (SACZ). The general aim of this work was to investigate the influence of spatial and temporal resolution of sea surface temperature (SST) data in simulating precipitation associated with SACZ. Simulations with the model BRAMS (Brazilian developments on the Regional Atmospheric Modeling System) were performed for two SACZ events, occurred in 1998 (El Niño) and 1999 (La Niña). The amount of accumulated precipitation in oceanic SACZ was larger in experiments with warmer SST. Statistical indices were used in order to verify the model's performance in the simulation of precipitation in the regions that compound SACZ (oceanic, coastal and amazon), with different SST datasets. Different time-space resolution of the SST data set does not have significant influence on the SACZ simulated with the BRAMS model. The model is more efficient in identifying occurrence/non-occurrence of rain than in localizing more intense nuclei, and its performance was better (worse) in amazon (oceanic) region of SACZ.
\end{abstract}

Keywords: numerical modeling, SACZ, SST, precipitation.

\section{INTRODUÇÃO}

Durante o verão austral, diversas regiões do Brasil sofrem períodos de intensa precipitação, o que ocasiona sérios problemas sociais e econômicos nas cidades e zonas rurais (Lima e Satyamurty, 2010). Grande parte dessas chuvas está geralmente associada à chamada Zona de Convergência do Atlântico Sul (ZCAS), que normalmente localiza-se sobre a Região Sudeste, norte do Paraná, sul da Bahia, e Brasil Central (Carvalho e Jones, 2009), provocando chuvas intensas e persistentes devido à sua manutenção durante vários dias sobre essas regiões. 
A ZCAS é descrita como região com alta variabilidade da atividade convectiva no leste da América do Sul durante o verão austral (Carvalho et al., 2004). Em campos de radiação de onda longa emergente (ROLE) média mensal é caracterizada por uma banda de ROLE mínima ligada à Amazônia, onde há intensa convecção (Ninomiya, 2007). Em imagens de satélite é destacada por uma extensa banda de nebulosidade com orientação noroeste-sudeste, que se estende do sul da Amazônia ao sudeste do Brasil e sudoeste do Atlântico Sul (Casarin e Kousky, 1986; Kodama, 1992, 1993; Ferreira et al., 2004).

Os regimes de precipitação da América do Sul variam em diferentes escalas espaço-temporais. A influência de fenômenos atmosféricos de escala global, como o El Niño-Oscilação Sul (ENOS), na variabilidade interanual da ZCAS foi estudada por diversos autores. Carvalho et al. (2004) mostraram que a(s) fase(s) quente (fria e neutra) do ENOS favorece (favorecem) a ocorrência de ZCAS oceânica (continental). Já Liebmann et al. (2001) destacaram que, durante o verão austral, a quantidade de eventos extremos interanuais de precipitação no Estado de São Paulo é positivamente correlacionada com as anomalias de temperatura da superfície do mar (TSM) no Pacífico equatorial.

Por outro lado, é importante destacar que a evolução dos fenômenos atmosféricos, em escalas mais regionais ou locais, depende fortemente das condições da superfície local, tais como temperatura, umidade do solo, vegetação, topografia e TSM. Desta forma, essas variáveis influenciam na representação adequada dos sistemas atmosféricos por modelos numéricos da atmosfera.

A influência das características da superfície oceânica na variabilidade da precipitação sobre a América do Sul foi estudada em muitos trabalhos. Barreiro et al. (2002), por exemplo, argumentaram que a variabilidade da precipitação sobre o oceano é mais influenciada pela TSM do que por variabilidades internas da atmosfera. Salientaram que a TSM pode influenciar na estabilidade atmosférica e no suprimento de umidade para a convecção profunda, desempenhando um importante papel na variabilidade da ZCAS oceânica, não influenciando de maneira significativa nas porções continentais. Em contrapartida, Barros et al. (2000) sugeriram que a TSM desempenha importante influência no deslocamento e intensidade da precipitação da ZCAS oceânica e, inclusive, da costeira.

Outros estudos ainda exploraram aspectos relativos ao acoplamento entre a ZCAS e a TSM do Atlântico, como Chaves e Nobre (2004) e Chaves e Satyamurty (2006). No primeiro trabalho, os autores mostraram que a intensificação da ZCAS tende a causar abaixamento da TSM na região sob o sistema devido à diminuição da incidência solar na superfície oceânica, causando anomalias negativas ou a desintensificação de anomalias positivas pré-existentes. Desta forma, observaram uma resposta oceânica à forçante atmosférica (nebulosidade associada à ZCAS). Essa interação entre oceano e atmosfera pode levar à desconfiguração dos processos que mantêm a ZCAS oceânica ativa: sem a diminuição da TSM, a ZCAS manter-se-ia por mais tempo (Jorgetti, 2008).

Em alguns trabalhos foram realizadas simulações da ZCAS com o uso de modelos atmosféricos. Nobre et al. (2002) utilizaram o modelo de circulação geral da atmosfera do CPTEC (MCGA-CPTEC) para estudar os efeitos de anomalias de TSM sobre o Atlântico Sudoeste na posição e intensidade da ZCAS. Seus resultados mostraram que anomalias positivas de TSM favorecem o aumento da convecção e movimento vertical ascendente sobre as águas aquecidas, aumentando consequentemente a subsidência compensatória principalmente ao norte da banda de nebulosidade mais intensa associada à ZCAS. Também utilizando MCGA-CPTEC, Chaves e Satyamurty (2006) mostraram que a formação da ZCAS independe dos padrões de TSM do Atlântico Sul. Contudo, estes padrões parecem ter importância na intensidade da convecção sobre o setor leste do continente e sobre a porção oceânica da ZCAS. Mais recentemente, Lima (2010) utilizou o modelo ETA-CPTEC em experimentos de sensibilidade para verificar os efeitos das anomalias e da resolução da TSM, bem como da topografia sobre episódios de precipitação intensa na região sudeste do Brasil, associados à ZCAS. Concluiu que a topografia foi mais importante do que a influência da TSM em um dos episódios analisados. Entretanto, em um segundo caso, ambos os fatores (topografia e anomalias de TSM com maior resolução espacial) tiveram papel importante, sendo que as anomalias positivas de TSM na região próxima do litoral induziram mudanças na estabilidade, afetando a atmosfera conforme foi visto nos valores de CAPE (Energia Potencial Convectiva Disponível) e CINE (Energia de Inibição Convectiva).

Especificamente utilizando o RAMS (Regional Atmospheric Modeling System), Calderon (2000) indicou que a TSM do Atlântico controla significativamente a precipitação sobre o oceano, ao longo da costa brasileira e também no interior do continente, sugerindo uma possível influência dos padrões de TSM na estrutura, intensidade e posicionamento da ZCAS. Jorgetti (2008) realizou simulações com o BRAMS (Brazilian developments on the Regional Atmospheric Modeling System), acoplado a um modelo de camada de mistura oceânica. Tais simulações representaram bem as circulações associadas ao Sistema de Monção da América do Sul, porém tenderam a subestimar a precipitação na região da ZCAS.

Atualmente existem diferentes conjuntos de dados de TSM disponíveis para serem utilizados como condição de fronteira inferior em modelos atmosféricos regionais. Em particular, a National Oceanic and Atmospheric Administration (NOAA) disponibiliza dados de TSM em duas resoluções espaçotemporais: semanal com 1 grau de espaçamento e diária com 0,25 graus de espaçamento. Usualmente é utilizado o conjunto de 
menor resolução e a questão que surge é se o uso de uma maior resolução desses dados poderia levar a uma melhor simulação da precipitação em episódios de ZCAS. Assim, o objetivo geral do presente trabalho foi verificar a influência da resolução espaçotemporal dos dados de TSM na simulação da precipitação associada a dois eventos de ZCAS, ocorridos em diferentes fases do ENOS. Além disso, pretendeu-se verificar estatisticamente o papel desses diferentes conjuntos de dados no desempenho do modelo BRAMS na simulação de precipitação nas três regiões que compõem a ZCAS (oceânica, costeira e amazônica).

\section{MATERIAL E MÉTODOS}

Os campos atmosféricos globais utilizados para a definição das condições iniciais e de fronteira do modelo numérico foram as Reanálises ERA-40 (Uppala et al., 2005), provindas de observações meteorológicas assimiladas no modelo global do European Centre for Medium-Range Weather Forecasts (ECMWF). Esse conjunto de dados encontra-se em grade regular com espaçamento de 1,125 graus, está disponível em superfície e 23 níveis de pressão para quatro horários diários $(00,06,12,18 \mathrm{Z})$ de setembro de 1957 a dezembro de 2002.

Foram utilizados dois conjuntos de dados de TSM, as análises semanais e as diárias da NOAA, em grade regular com espaçamento de 1 grau (Reynolds et. al, 2002) e de 0,25 graus (Reynolds et al., 2007), respectivamente. O primeiro está disponível para o período de novembro de 1981 ao presente e o segundo de janeiro de 1985 ao presente.

Ambos os conjuntos de dados de TSM foram construídos através de interpolação ótima, utilizando dados in situ de navios e boias e também dados de satélite do sensor Advanced Very High Resolution Radiometer (AVHRR) no canal infravermelho, incluindo um ajuste de grande escala do viés do satélite com relação aos dados in situ (Reynolds et al., 2007). Segundo esse trabalho, as regiões com as maiores diferenças entre esses conjuntos de dados de TSM ocorrem entre $60^{\circ} \mathrm{S}$ e $40^{\circ} \mathrm{S}$ com os maiores valores no Pacífico leste. Esta é a região onde a cobertura de dados in situ é mais escassa, consequentemente, a determinação do viés é mais difícil e sua correção é menos eficiente em comparação com outras regiões do globo. Além disso, os gradientes de TSM são mais intensos nos dados com maior resolução espaço-temporal (diários de 0,25 graus), com relação aos dados semanais de 1 grau.

As informações de tipos de solo, tipos de vegetação e topografia utilizadas para definir as condições de fronteira inferior do modelo regional foram baseadas nos dados fornecidos pelo United States Geological Survey/Earth Resources Observation and Science (USGS/EROS) Center.

Os dados de precipitação diária foram obtidos do Global Precipitation Climatology Project (GPCP) GOES Precipitation
Index (GPI) (Huffman et al., 2001), em grade regular com espaçamento de 1 grau, disponíveis de $40^{\circ} \mathrm{S}$ a $40^{\circ} \mathrm{N}$ e de 180 ${ }^{\circ} \mathrm{W}$ a $180^{\circ} \mathrm{E}$. Esses dados serão, neste trabalho, assumidos como sendo a precipitação "observada", para fins de comparação com a precipitação simulada pelo modelo, já que tem boa correlação com observações em pluviômetros (Joyce e Arkin, 1997) e por estarem disponíveis também sobre regiões oceânicas. O período de estudo corresponde a dois episódios de ZCAS, selecionados com base no Climanálise - Boletim de Monitoramento e Análise Climática do CPTEC/INPE. Um dos episódios ocorreu durante um El Niño (12-16 de fevereiro de 1998) e outro durante uma La Niña (6-18 de janeiro de 1999), daqui em diante referidos como ZCAS-98 e ZCAS-99, respectivamente. Os critérios utilizados para definir os episódios de ZCAS podem ser vistos em referências tais como as de Quadro (1994), Ferreira et al. (2004) e Sacramento Neto et al. (2010).

\subsection{Descrição dos experimentos numéricos}

O modelo utilizado no presente trabalho foi o BRAMS versão $4.2^{1}$, derivado do RAMS versão 5.04. É um modelo de mesoescala criado pela Colorado State University, Estados Unidos (Pielke et al., 1992; Cotton et al., 2003) e foi desenvolvido pelo Projeto "BRAMS - adaptação do RAMS às características brasileiras", coordenado pelo CPTEC/INPE e financiado pela Financiadora de Estudos e Projetos (FINEP). O modelo BRAMS é baseado no esquema de diferenças finitas, não-hidrostático, compressível, de área limitada e inclui equações prognósticas para água em suas três fases, temperatura e as três componentes do vento (Tripoli e Cotton, 1982; Tremback, 1990; Walko et al., 1995, 2000).

Foram realizados três experimentos numéricos distintos para os dois eventos de ZCAS selecionados. A grade utilizada nas simulações abrangeu todo o Brasil, parte da América do Sul e de oceanos adjacentes, cobrindo uma área de 5.568 x 6.080 $\mathrm{km}^{2}$ (Figura 1). O espaçamento horizontal da grade foi de 32 $\mathrm{km}$, cujas matrizes horizontais incluíram 191x175 pontos e 34 níveis na vertical. $\mathrm{O}$ espaçamento da primeira camada vertical foi de 100 metros, com aumento sucessivo por um fator de 1,15 até atingir uma espessura de 1000 metros, a partir do qual esse espaçamento foi mantido até o topo do modelo. O centro e o polo de projeção da grade foram definidos no mesmo ponto: $17,5^{\circ} \mathrm{S}$ e $49,5^{\circ} \mathrm{W}$.

Os períodos de integração do modelo foram de 264 horas (11 dias), iniciando em 8 de fevereiro de 1998 às 00Z, para ZCAS-98, e de 384 horas (16 dias), iniciando em 2 de janeiro de 1999 às 00Z, para ZCAS-99. O passo de tempo utilizado foi

1. Disponível em http://brams.cptec.inpe.br/, acessado em outubro de 2012 
(a)

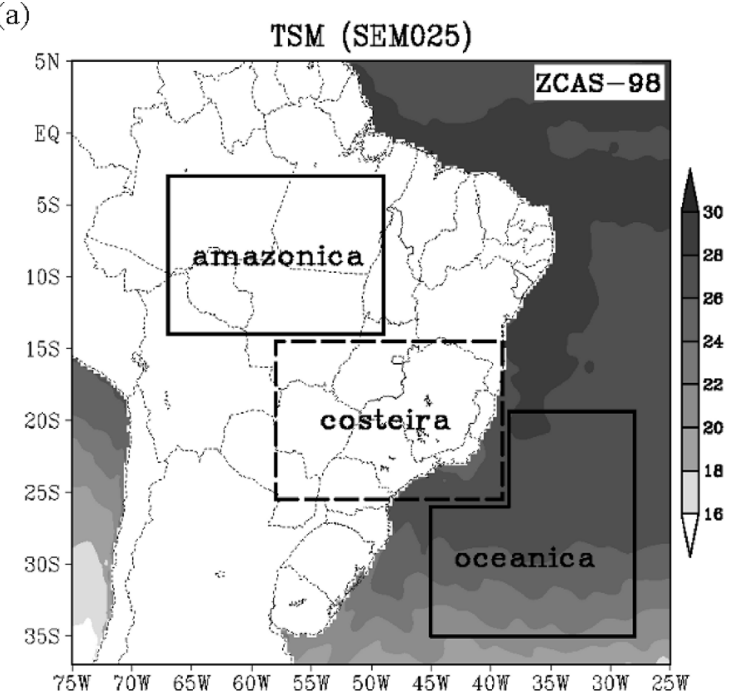

(c)

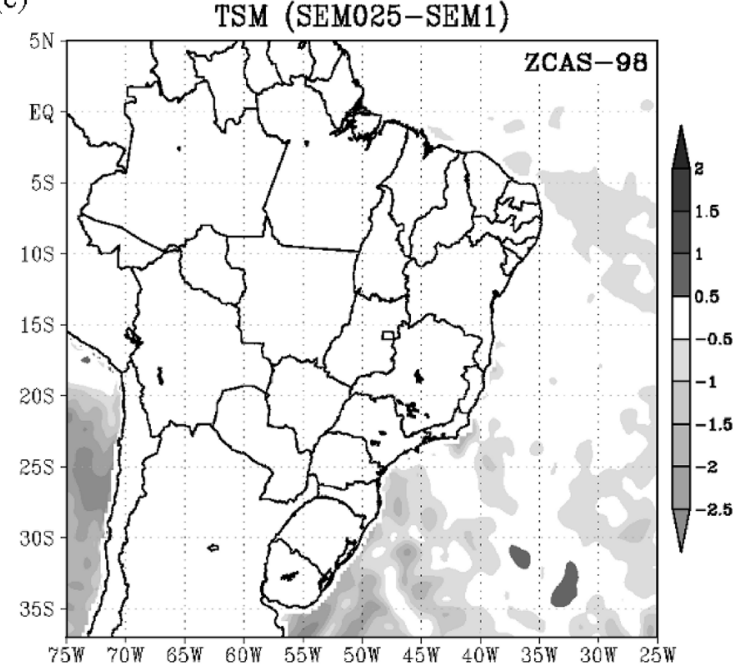

(b)

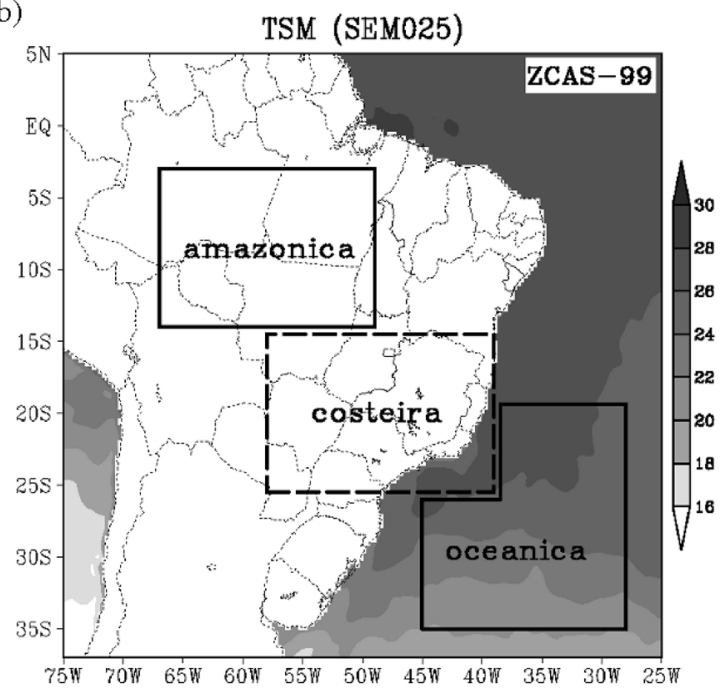

(d)

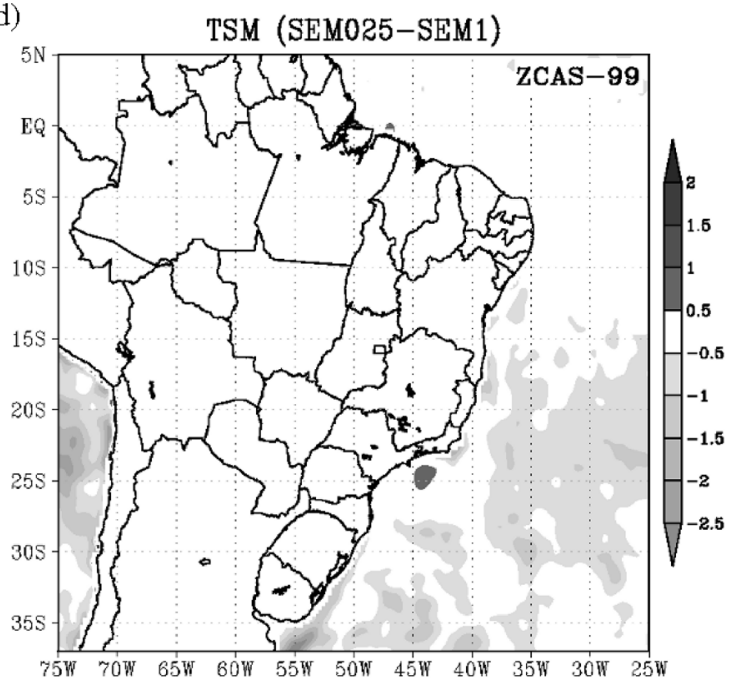

Figura 1 - Temperatura da superfície do mar (TSM) para os experimentos SEM025, média para o período de (a) 08 a 18 de fevereiro de 1998 e de (b) 02 a 17 de janeiro de 1999 e diferença da TSM para os mesmos períodos, entre os experimentos numéricos SEM025 e SEM1 para (c) ZCAS-98 e (d) ZCAS-99. Os retângulos em (a) e (b) representam os limites das regiões que compõem a ZCAS (amazônica, costeira e oceânica) utilizadas na análise estatística do desempenho do modelo.

de 30 segundos. As escalas de tempo de relaxamento (nudging) na fronteira lateral, no centro e no topo do modelo foram de $1.800,43.200$ e 10.800 segundos, respectivamente. O nudging foi aplicado em cinco pontos da fronteira lateral e a partir da altura de 16.000 metros. Foram utilizadas as parametrizações de cumulus de Grell (1993) e de radiação de onda curta e longa de Chen e Cotton (1983).

Cada experimento realizado para os dois casos de ZCAS utilizou como condição inicial um conjunto de dados de TSM diferente, sendo que os valores das temperaturas na superfície do mar variavam durante a simulação, conforme o conjunto de dados. Em um dos experimentos a TSM utilizada foi a semanal com espaçamento regular de 1 grau, daqui em diante referido como experimento SEM1. Outro experimento utilizou dados de TSM diária com espaçamento regular de 0,25 graus, daqui em diante referido como DIA025. O último experimento utilizou como condição inicial de TSM um conjunto de dados semanais com espaçamento regular de 0,25 graus e será referido como experimento SEM025. As diferenças entre as três simulações (SEM025, SEM1 e DIA025) estão resumidas na Tabela 1.

Tabela 1 - Denominação e diferenças entre os experimentos numéricos.

\begin{tabular}{c|c|c|c}
\cline { 2 - 4 } & SEM025 & SEM1 & DIA025 \\
\hline resolução espacial da TSM & $0,25^{\circ} \times 0,25^{\circ}$ & $1^{\circ} \times 1^{\circ}$ & $0,25^{\circ} \times 0,25^{\circ}$ \\
resolução temporal da TSM & semanal & semanal & diária \\
\hline
\end{tabular}


Deve-se observar que o conjunto de dados de TSM semanal, na grade regular com espaçamento de 0,25 graus (utilizado no experimento SEM025), foi construído através do cálculo de médias de sete dias dos dados de TSM diária na grade regular com espaçamento de 0,25 graus (utilizado em DIA025). As médias foram calculadas de forma coerente com as TSM semanais com espaçamento de 1 grau (utilizados em SEM1), isto é, sendo $i$ o dia central de cada semana a que se refere o campo de TSM semanal de 1 grau, as médias dos dados diários de 0,25 graus foram computadas do dia $i-3$ ao dia $i+3$ de cada semana.

Com base na Figura 14 de Reynolds et al. (2007), as maiores diferenças entre os dados originais de TSM da NOAA, isto é, os utilizados em SEM1 e DIA025, encontram-se na região das Correntes de Kuroshio, do Labrador e do Leste da Groenlândia e nos subtrópicos do Hemisfério Sul, principalmente no Pacífico leste subtropical deste hemisfério. Nas regiões do Hemisfério Sul, as TSM semanais de 1 grau apresentam-se, sobretudo, mais altas do que as TSM diárias de 0,25 graus.

As Figuras 1a e 1b mostram, respectivamente, as TSM dos experimentos SEM025, médias para o período de 08 a 18 de fevereiro de 1998 e para o período de 02 a 17 de janeiro de 1999. Comparando-se os dois períodos, em 1998 as TSM no Atlântico apresentavam um maior gradiente na região subtropical e temperaturas mais altas, de até 2 graus, na costa norte e nordeste do Brasil. Em relação às diferenças entre os experimentos, especificamente para o período do evento ZCAS98, a TSM em SEM1 foi até $2,5{ }^{\circ} \mathrm{C}$ mais quente do que em SEM025 no Atlântico Sul e Pacífico Sul (Figura 1c). Observa-se o mesmo comportamento na região do Atlântico equatorial, no entanto essa diferença é da ordem de $1^{\circ} \mathrm{C}$. Para a ZCAS-99, as diferenças entre as TSM concentram-se no Atlântico subtropical e também no Pacífico Sul (Figura 1d). Não são mostradas as diferenças entre as TSM dos experimentos SEM025 e DIA025, uma vez que o conjunto de dados de TSM semanal utilizado no primeiro foi construído a partir dos dados diários empregados no segundo e suas diferenças são mínimas.

\subsection{Descrição da análise estatística}

Tendo em vista a grande variabilidade espacial da precipitação ao longo da ZCAS, foram definidas três regiões distintas que a compõem, denominadas oceânica, costeira e amazônica (Figura 1). Essas regiões foram determinadas com base em Carvalho et al. (2004) e foi analisada a precipitação acumulada para cada uma dessas regiões.

As grades dos dados do GPI e das saídas do modelo foram transportadas para uma mesma grade regular com espaçamento de 0,3 graus e acumulações diárias (das $00 \mathrm{Z}$ de um dia às $00 \mathrm{Z}$ do dia seguinte) da precipitação simulada para cada experimento foram calculadas, a fim de possibilitar a comparação dos pontos de grade simulados e observados correspondentes.

Para avaliar objetivamente as simulações de precipitação do modelo, foram calculados os índices estatísticos Erro Médio (EM), RaizQuadrada doErro Médio Quadrático-RootMean Square Error (RMSE) em inglês e Bias-Adjusted Threat Score (TSA). O índice estatístico EM (Wilks, 2006) pode ser definido como:

$$
E M=\frac{1}{n} \sum_{i=1}^{n}\left(y_{i}-o_{i}\right)
$$

e o índice RMSE (Pielke, 2002) como:

$$
R M S E=\sqrt{\frac{1}{n} \sum_{i=1}^{n}\left(y_{i}-o_{i}\right)^{2}}
$$

onde $n$ é o número de instantes da análise/observação e $y_{i}$ e $o_{i}$ são os valores simulados e observados, respectivamente, para cada ponto de grade.

O EM fornece uma medida do viés da simulação, sendo que valores positivos (negativos) indicam superestimativa (subestimativa). O RMSE é uma medida da acurácia do modelo, que é o quanto o resultado de uma simulação é próximo do valor verdadeiro. Quanto maiores os valores de RMSE, menor é a acurácia do modelo na simulação da quantidade de chuva.

Finalmente o TSA é um índice que mede a habilidade do modelo em prever e sua acurácia em localizar eventos classificados em categorias; quanto mais próximo de 1, melhor é a previsão da localização de precipitação do modelo. O TSA (Baldwin e Kain, 2006) é definido como:

$$
T S A=\frac{1-\left(\frac{O-H}{O}\right)^{O / F}}{1+\left(\frac{O-H}{O}\right)^{O / F}}
$$

onde $F, O$ e $H$ são os números de pontos da grade com precipitação prevista, observada e prevista corretamente pelo modelo (hits), respectivamente, acima de determinado limiar. Valores de TSA iguais a -9999 indicarão que não foi possível calcular o índice, devido à ocorrência de divisão por zero em pelo menos uma das razões contidas na Equação 3.

Os índices foram calculados para cada uma das regiões que compõem a ZCAS (Figura 1) e para limiares ou categorias de precipitação adotadas pelo National Centers for Environmental Prediction (NCEP).

\section{RESULTADOS E DISCUSSÃO}

Esta seção descreve os resultados das simulações numéricas para os dois eventos de ZCAS estudados neste 
trabalho. Além disso, apresenta resultados relativos ao desempenho estatístico do modelo BRAMS na simulação de precipitação ao longo da ZCAS para o evento ZCAS-98, com o uso das diferentes condições de contorno de TSM.

\subsection{Resultados das simulações numéricas}

A Figura 2 mostra a precipitação media diária produzida pelos experimentos SEM025, durante os dois períodos simulados, bem como a precipitação observada nesses períodos através do GPI. Qualitativamente pode-se observar que, para ambos os casos, o modelo conseguiu simular a banda de precipitação associada à ZCAS, desde sua parte oceânica até a região amazônica, embora superestimando os valores absolutos

(a)

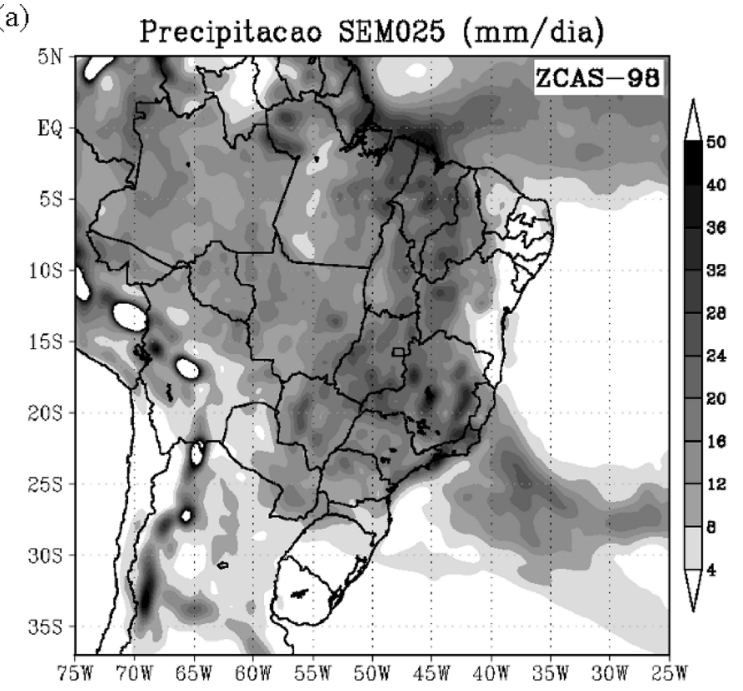

(c)

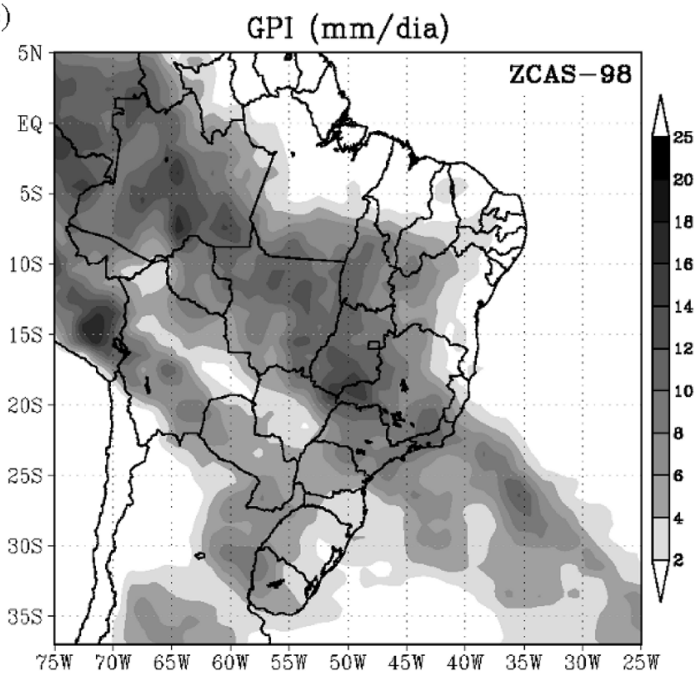

da precipitação média diária no período. Em alguns pontos isolados, por exemplo, nas encostas lestes dos Andes e na foz do Rio Amazonas no caso da ZCAS-99, o modelo chegou a simular precipitações médias diárias maiores que $50 \mathrm{~mm} \mathrm{dia}^{-1}$, o que não foi observado com o GPI. Nota-se também que, embora não tenha sido observada precipitação pelo GPI na região norte do Brasil e no Atlântico equatorial no caso da ZCAS-98 (Figura 2c), o modelo simulou precipitação nessas regiões. Por outro lado, sobre a região da ZCAS, nota-se que o modelo conseguiu simular seu posicionamento mais deslocado para a região equatorial no caso de 1998, comparado com o de 1999, que teve sua localização mais sobre o Estado de São Paulo e norte do Mato Grosso do Sul. As precipitações médias diárias simuladas com os outros experimentos (SEM1 e DIA025) não são apresentadas pois, no

(b)

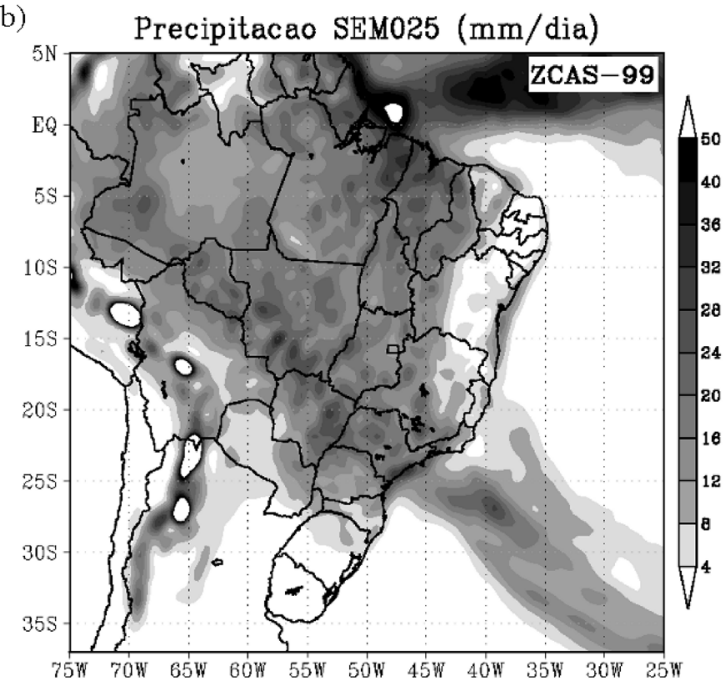

(d)

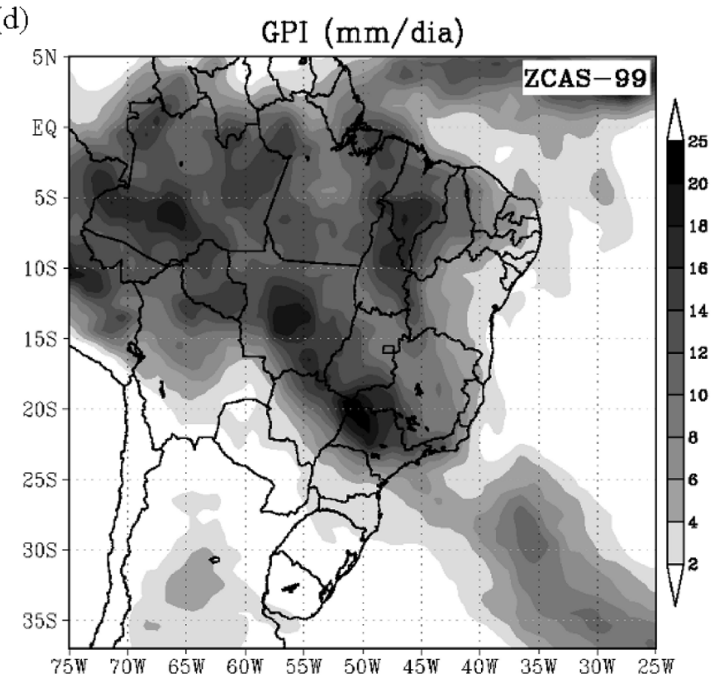

Figura 2 - Precipitação média diária $\left(\mathrm{mm} \mathrm{dia}^{-1}\right)$ simulada com o experimento SEM025 para o período de (a) 08 a 18 de fevereiro de 1998 e para o período de (b) 02 a 17 de janeiro de 1999. Os painéis (c) e (d) mostram a precipitação média diária para os mesmos períodos, respectivamente, mas dada por observações de satélite (GPI). 
geral, são muito semelhantes à simulação SEM025. As diferenças entre as simulações serão apresentadas a seguir.

Na comparação dos resultados entre os três conjuntos de experimentos, os painéis da Figura 3 mostram as diferenças na precipitação total acumulada nos períodos de integração do modelo. Observa-se que o experimento com TSM de menor resolução (SEM1) produz mais precipitação sobre a região da ZCAS e da Zona de Convergência Intertropical (ZCIT) no evento de 1998 (Figura 3a) e sobre a ZCAS em 1999 (Figura 3b). Além disso, as diferenças possuem padrões mais regulares sobre a parte oceânica da ZCAS, tornando-se mais aleatórias e menos evidentes quando se observa, sucessivamente, a região costeira e amazônica da ZCAS. Essas evidências já indicam, tal como no trabalho de Barreiro et al. (2002), que a maior quantidade de precipitação na região da ZCAS oceânica ocorre devido à maior TSM, que induz

(a)

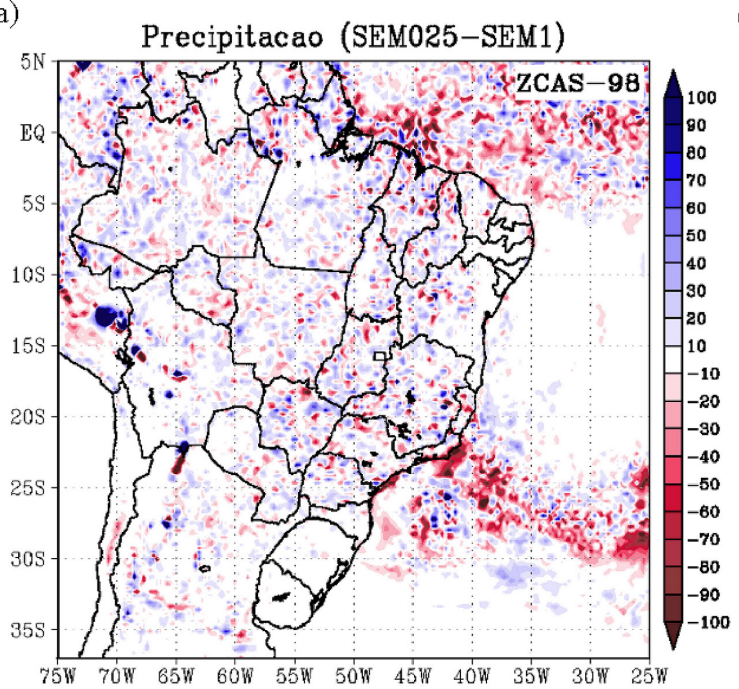

(c)

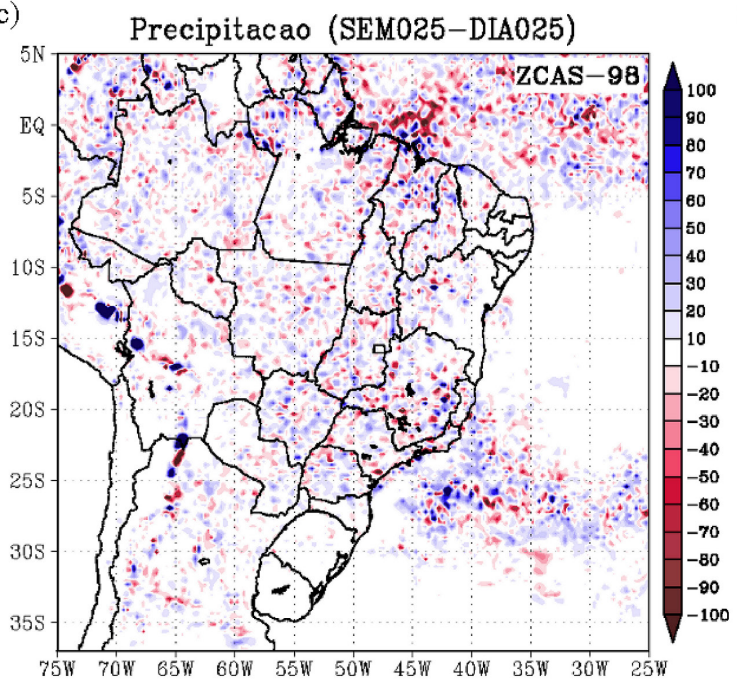

maior evaporação e, portanto, maior fornecimento de umidade para a zona de convergência principalmente nos níveis mais baixos.

As diferenças entre os experimentos SEM025 e DIA025 (Figura 3c e 3d) são menores do que entre SEM1 e SEM025, até porque a TSM de SEM025 foi construída a partir da TSM utilizada em DIA025. Porém, o mesmo padrão observado entre os experimentos SEM025 e SEM1 é identificado nas Figuras 3c e 3d, sendo que a precipitação acumulada na região de ZCAS oceânica é em geral maior em SEM1 e SEM025 do que em DIA025.

A precipitação no modelo BRAMS pode ser gerada por dois esquemas de parametrização: uma parametrização de microfísica de nuvens e precipitação explícita e outro de parametrização convectiva. No caso da parametrização convectiva, foi utilizado neste trabalho o chamado esquema de Grell (1993), onde a precipitação é determinada por uma

(b)

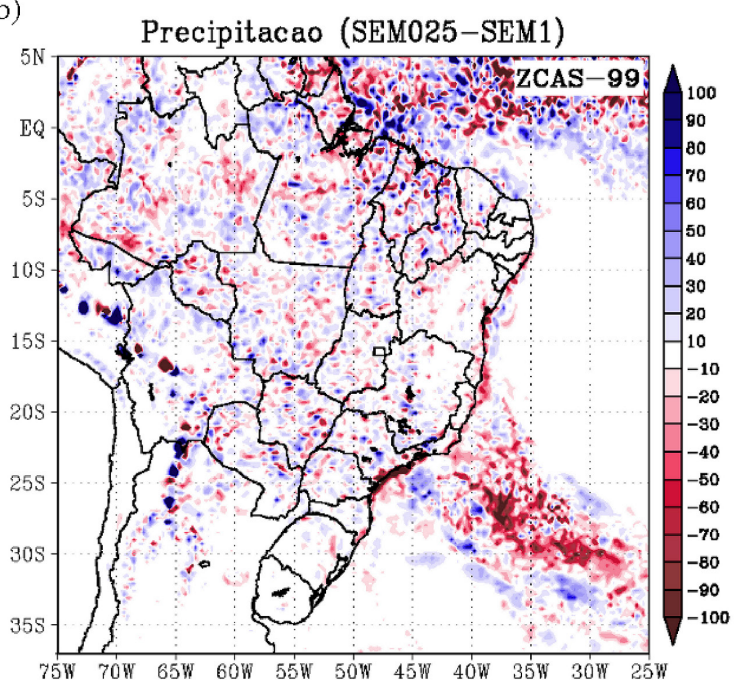

(d)

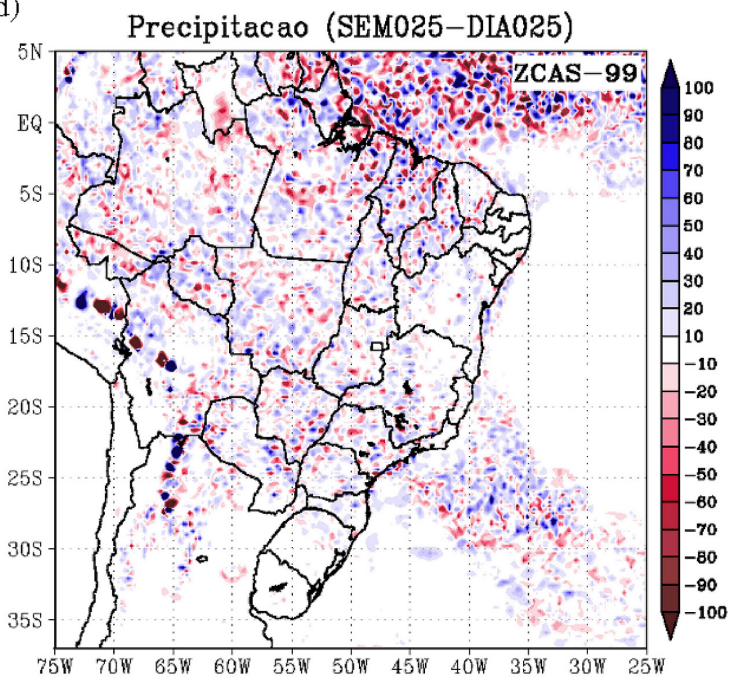

Figura 3 - Diferença da precipitação acumulada no final dos períodos de integração do modelo entre os experimentos numéricos SEM025 e SEM1 para (a) ZCAS-98 e (b) ZCAS-99 e entre SEM025 e DIA025 para (c) ZCAS-98 e (d) ZCAS-99. 
hipótese de quase-equilíbio em que a estabilização vertical da coluna atmosférica é feita pela convecção, na mesma taxa em que é desestabilizada pelo escoamento de grande escala. Uma análise em separado dos dois tipos de precipitação produzida nas simulações efetuadas neste trabalho, com o espaçamento horizontal adotado $(32 \mathrm{~km})$ e principalmente nas regiões tropical e subtropical, mostrou que a precipitação é praticamente gerada pela parametrização convectiva. Assim, as diferenças observadas nos campos de precipitação são basicamente determinadas pela maior ou menor instabilidade atmosférica, ligada ao aquecimento e/ou umedecimento das camadas mais baixas da atmosfera. Esses aspectos serão analisados a seguir.

O fluxo de calor sensível é maior em SEM1 do que em SEM025 na região oceânica (Figuras 4a e 4b), consistentemente com as regiões de maior TSM em SEM1. O fluxo de calor sensível em regiões com TSM mais elevada é maior, aquecendo mais eficientemente o ar adjacente à superfície do mar e induzindo maior abaixamento de pressão em baixos níveis em SEM1 (figura não incluída). Além disso, o maior aquecimento em SEM1 sobre o oceano promove a desestabilização das camadas mais baixas da atmosfera, o que pode ser corroborado pelo maior valor de CAPE neste experimento (figura não incluída), uma vez que o CAPE está associado à estabilidade atmosférica. Como o esquema de parametrização convectiva utilizado nas simulações (esquema de Grell) está associado com a desestabilização da atmosfera em baixos níveis, seu acionamento é mais frequente em SEM1 do que em SEM025. As diferenças entre SEM025 e DIA025 concentram-se sobre

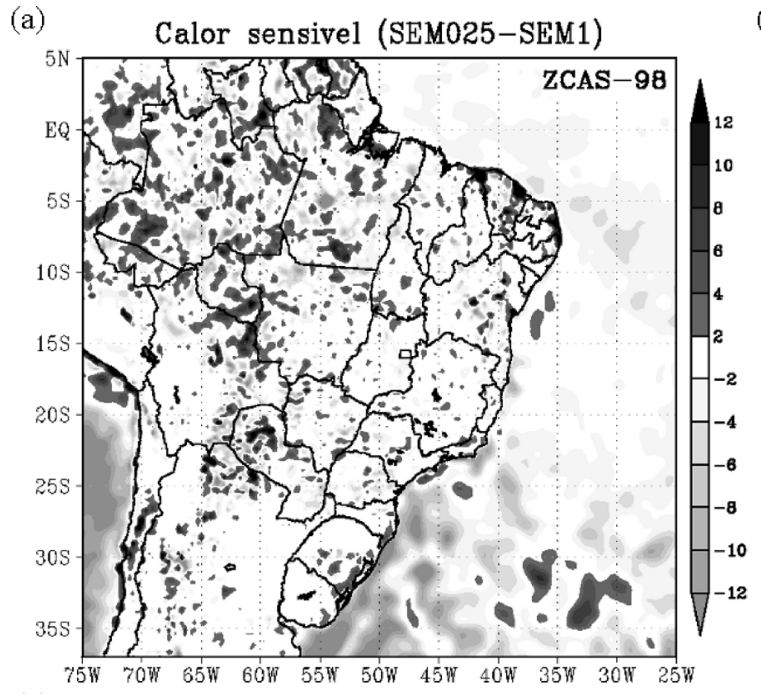

(b)

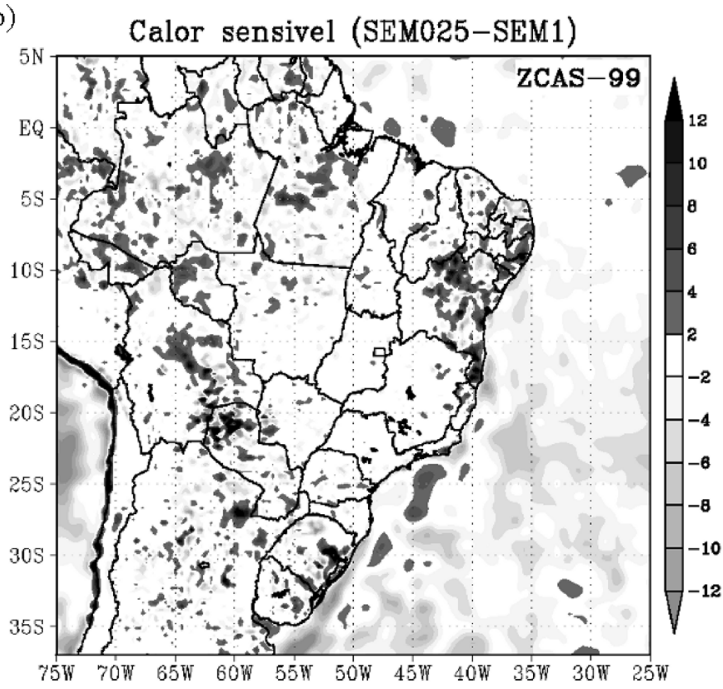

(c)
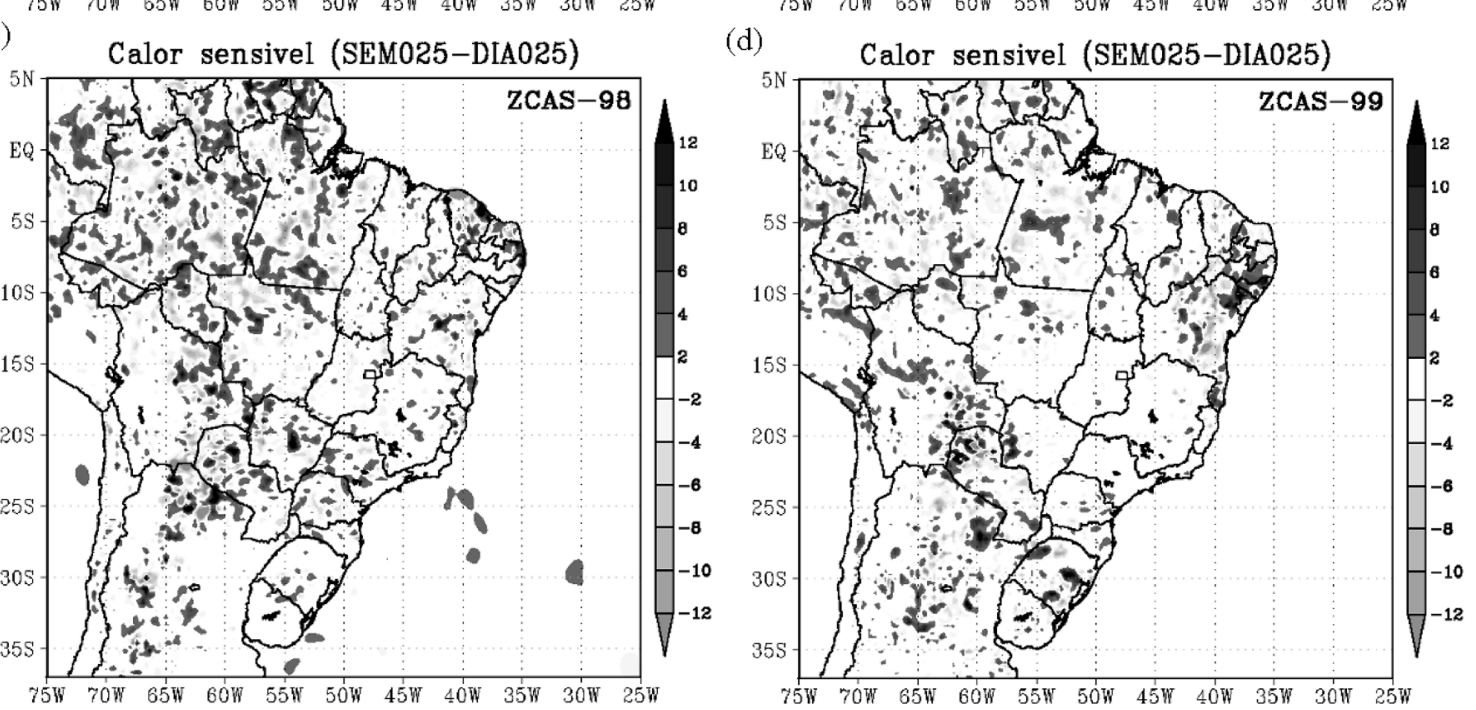

Figura 4 - Diferença da média do fluxo de calor sensível à superfície entre os experimentos numéricos SEM025 e SEM1 para (a) ZCAS-98 e (b) ZCAS-99 e entre SEM025 e DIA025 para (c) ZCAS-98 e (d) ZCAS-99. As médias referem-se a todo período de integração do modelo para cada caso. 
o continente (Figuras $4 \mathrm{c}$ e 4d), e ocorrem devido às diferentes quantidades de precipitação entre os experimentos, conforme será mostrado mais adiante. A precipitação irá determinar a umidade do solo, que por sua vez definirá a partição do saldo de radiação entre os fluxos de calor sensível e latente à superfície.

O fluxo de calor latente em SEM1 é mais intenso do que em SEM025 (Figuras 5a e 5b) sobre os oceanos. As diferenças entre esses experimentos são da ordem de $50 \mathrm{~W} \mathrm{~m}^{-2}$ ou superior sobre as regiões onde a TSM em SEM1 é mais quente com relação a SEM025. Maior temperatura e escoamento mais intenso estão associados a maior evaporação. Regiões com maior temperatura a 2 metros da superfície (figura não incluída) em SEM1 coincidem com as regiões de maior TSM neste experimento (Figura 1c), quando comparado a SEM025. Por outro lado, diferenças de escoamento entre os experimentos não representam papel significativo nas diferenças de evaporação
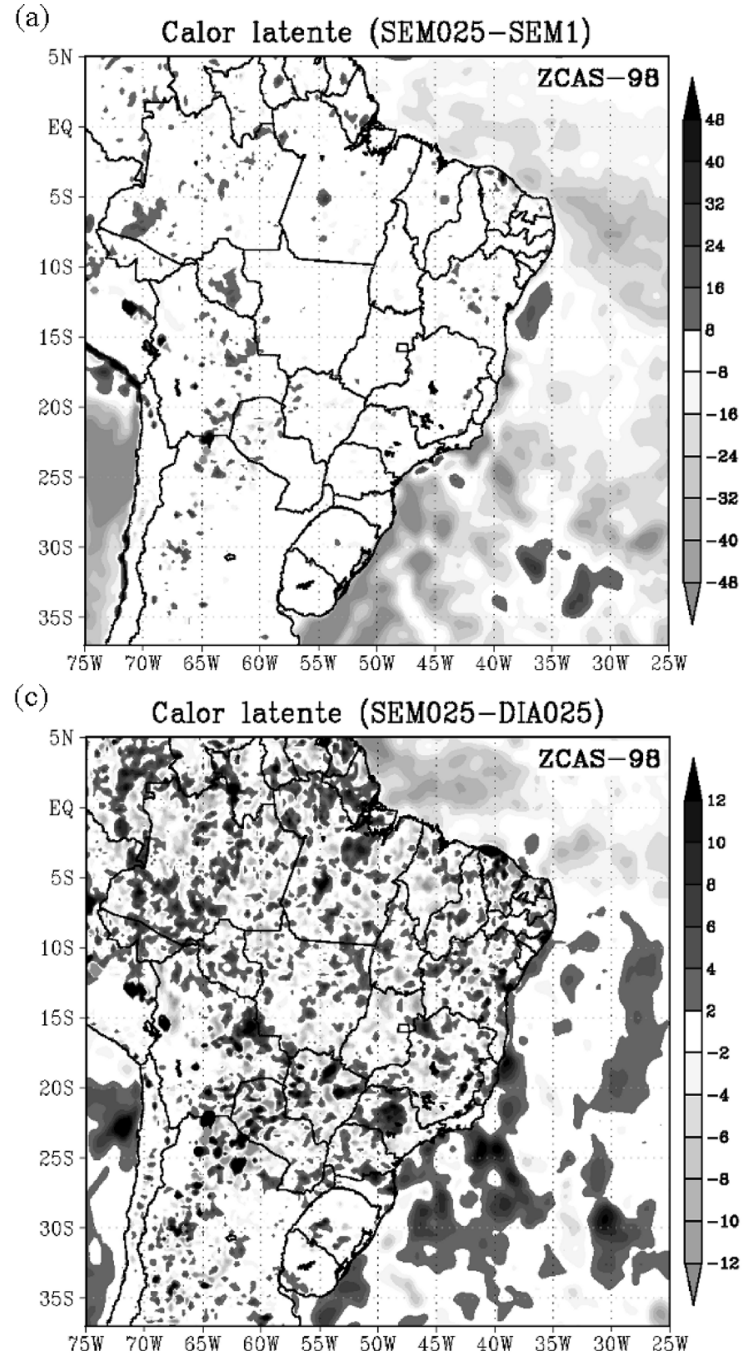

(figura não incluída). Tendo em vista a maior importância da temperatura para este processo no caso das simulações, a evaporação em SEM1 é mais eficiente do que em SEM025, indicando um maior suprimento de umidade para a formação de precipitação associada à ZCAS no primeiro experimento, conforme constatado pelos maiores valores de água precipitável na região (figura não incluída).

Apesar do conjunto de dados de TSM em SEM025 ter sido construído a partir do utilizado em DIA025, o fluxo de calor latente é mais intenso no primeiro no Atlântico Sul e Pacífico Sul (Figuras 5c e 5d). As diferenças nos fluxos médios entre esses experimentos ocorrem devido às diferentes frequências de atualização da TSM durante as simulações, que ocorre a cada sete dias em SEM025 e diariamente em DIA025. A TSM em SEM025 permaneceu superior à TSM de DIA025 por um período de tempo mais longo, conforme é possível constatar com (b)

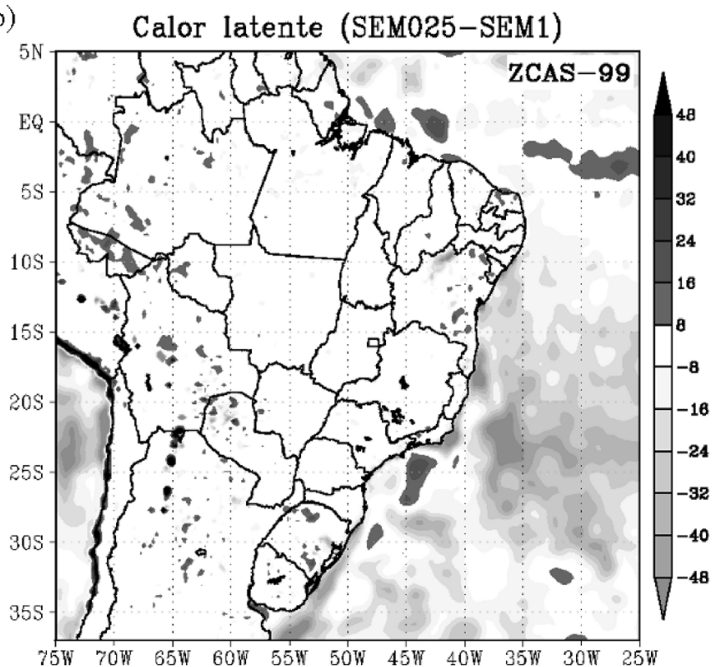

(d)

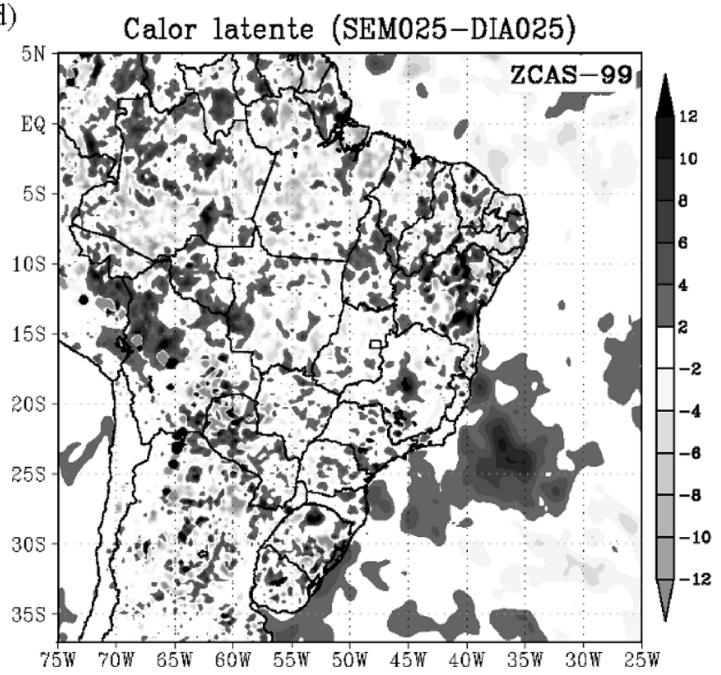

Figura 5 - Idem à Figura 4, mas para fluxo de calor latente à superfície. Observar que as escalas de cinza são diferentes entre (a)-(b) e (c)-(d). 
base na série temporal da TSM para um ponto localizado no Atlântico Sul (figura não incluída). Por outro lado, no Atlântico equatorial observa-se o oposto. No Atlântico Sul ocorre maior evaporação em SEM025 e, como consequência, maior aporte de umidade realizado pela circulação da Alta Subtropical do Atlântico Sul para a região de atuação da ZCAS. Para o experimento DIA025 para o caso ZCAS-98 (Figura 5c), o maior suprimento de umidade ocorre na região da ZCIT do Atlântico.

A maior quantidade de precipitação em SEM1 na região da ZCAS oceânica (Figuras 3a e 3b) ocorre devido à maior TSM observada neste experimento (Figuras 1c e 1d). A TSM mais quente induz à maior evaporação, conforme já observado com base no fluxo de calor latente (Figuras 5a e 5b), ocorrendo maior fornecimento de umidade em baixos níveis para a zona de convergência. Além disso, o maior aquecimento instabiliza as camadas mais baixas da atmosfera do modelo, favorecendo a ocorrência da precipitação convectiva. Esse resultado é similar ao apontado por Barreiro et al. (2002). Os experimentos que apresentam maior e menor quantidade de precipitação na ZCAS oceânica foram SEM1 e DIA025, respectivamente (Figuras 3a, 3b, 3c e 3d).

Conforme foi possível observar, os resultados para o evento de ZCAS ocorrido durante a La Niña (ZCAS-99) foram semelhantes aos obtidos para o caso que ocorreu durante a fase quente do ENOS (ZCAS-98).

\subsection{Desempenho do modelo BRAMS na simulação de precipitação na ZCAS}

O conhecimento do desempenho de um modelo atmosférico na simulação de sistemas de tempo que afetam fortemente a população e a economia do país, como a ZCAS, tem grande importância, pois auxilia na melhora da representação desses sistemas pelo modelo. A escolha de condições de contorno mais adequadas, para a representação de determinado sistema, tem importante papel no progresso da pesquisa científica na área de modelagem atmosférica e, consequentemente, na melhora da previsão de tempo. Pelo BRAMS ser um modelo amplamente utilizado em estudos científicos produzidos no Brasil e ter importante papel no avanço de descobertas na área de meteorologia e climatologia, foi realizada a análise estatística descrita em detalhes na seção 2.2 para avaliação do desempenho do modelo na simulação da ZCAS com as diferentes condições de contorno de TSM.

Em relação ao viés do modelo em simular a precipitação, os valores de EM para os três experimentos para ZCAS-98 (Tabela 2), mostram que este é dependente do limiar de chuva adotado. O modelo superestima (subestima) a precipitação para limiares inferiores (superiores), independentemente da região da ZCAS e dos dados de TSM, uma vez que EM apresenta valores positivos (negativos) para os limiares mais baixos (altos) de precipitação. Para o caso da ZCAS-99 (tabela não incluída) observa-se a mesma situação.

Valores gradativamente crescentes de RMSE (Tabela 2), dos limiares mais baixos para os mais altos, indicam que a acurácia do modelo na simulação de precipitação é maior para os limiares inferiores, decrescendo para os limiares superiores. Observa-se também que a acurácia do modelo é superior na região amazônica com relação às regiões oceânica e costeira, visto que os valores de RMSE para essas duas regiões são maiores do que os valores para a amazônica, com exceção do limiar de 38,1 $\mathrm{mm} \mathrm{dia}^{-1}$. Resultados semelhantes foram obtidos para o caso ZCAS-99.

Tabela 2 - EM e RMSE para limiares de precipitação, nas três regiões que compõem a ZCAS e nos três experimentos numéricos para ZCAS-98.

\begin{tabular}{|c|c|c|c|c|c|c|c|}
\hline & \multirow{2}{*}{\multicolumn{2}{|c|}{ SEM025 }} & \multirow{2}{*}{\multicolumn{2}{|c|}{ SEM1 }} & \multirow{2}{*}{\multicolumn{2}{|c|}{ DIA025 }} \\
\hline & & & & & & & \\
\hline Região & $\begin{array}{c}\text { Limiar } \\
\left(\mathrm{mm} \mathrm{dia}^{-1}\right)\end{array}$ & EM & RMSE & EM & RMSE & EM & RMSE \\
\hline \multirow{4}{*}{ 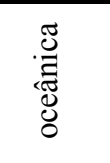 } & 0,3 & 5,0 & 14,0 & 5,1 & 14,4 & 4,9 & 13,8 \\
\hline & 6,3 & 1,9 & 16,5 & 1,6 & 16,7 & 1,7 & 16,2 \\
\hline & 19,0 & $-8,1$ & 18,4 & $-8,3$ & 18,7 & $-8,3$ & 17,8 \\
\hline & 38,1 & $-18,7$ & 21,3 & $-20,9$ & 21,3 & $-18,9$ & 20,7 \\
\hline \multirow{4}{*}{$\begin{array}{l}\frac{\pi}{0} \\
\frac{\mathbb{E}}{0} \\
0\end{array}$} & 0,3 & 9,2 & 16,3 & 9,6 & 16,8 & 9,0 & 16,0 \\
\hline & 6,3 & 4,6 & 14,2 & 5,0 & 14,6 & 4,3 & 13,9 \\
\hline & 19,0 & $-2,3$ & 14,3 & $-1,7$ & 14,5 & $-2,7$ & 14,0 \\
\hline & 38,1 & $-13,6$ & 20,5 & $-13,5$ & 20,6 & $-14,8$ & 20,7 \\
\hline \multirow{4}{*}{ 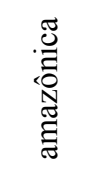 } & 0,3 & 5,1 & 12,0 & 5,1 & 11,9 & 5,1 & 12,0 \\
\hline & 6,3 & 1,8 & 10,9 & 1,7 & 10,8 & 1,7 & 10,8 \\
\hline & 19,0 & $-10,1$ & 12,5 & $-10,1$ & 12,8 & $-10,0$ & 12,6 \\
\hline & 38,1 & $-30,7$ & 30,7 & $-31,3$ & 31,3 & $-31,6$ & 31,6 \\
\hline
\end{tabular}


Em relação aos conjuntos de TSM utilizados, o experimento com desempenho inferior (superior) para as regiões oceânica e costeira é SEM1 (DIA025), pois apresenta valores de RMSE mais elevados (baixos) com relação aos demais experimentos. No entanto, destaca-se que as diferenças entre os valores desses índices para os diferentes experimentos encontram-se na primeira casa decimal para a maioria dos limiares, representando, desta forma, impacto pouco significativo na simulação da precipitação acumulada.

Observa-se que os melhores valores de TSA (próximos ou iguais a 1) ocorrem para os limiares mais baixos de chuva nos três experimentos (Tabela 3), principalmente para o limiar

Tabela 3 - TSA para limiares de precipitação, nas três regiões que compõem a ZCAS e nos três experimentos numéricos para ZCAS-98. Os dias correspondem aos dias simulados do mês de fevereiro de 1998. Valores iguais a -9999 indicam que não foi possível calcular o índice.

\begin{tabular}{|c|c|c|c|c|c|c|}
\hline Região & Limiar $\left(\mathrm{mm} \mathrm{dia}^{-1}\right)$ & dia 12 & dia 13 & dia 14 & dia 15 & dia 16 \\
\hline \multicolumn{7}{|c|}{ SEM025 } \\
\hline . & $\begin{array}{c}0,3 \\
6,3 \\
19,0 \\
38,1\end{array}$ & $\begin{array}{c}0,7 \\
0,5 \\
0,5 \\
-9999\end{array}$ & $\begin{array}{c}0,6 \\
0,5 \\
0,0 \\
-9999\end{array}$ & $\begin{array}{c}0,7 \\
0,5 \\
0,0 \\
-9999\end{array}$ & $\begin{array}{c}0,6 \\
0,5 \\
0,1 \\
-9999\end{array}$ & $\begin{array}{c}0,5 \\
0,2 \\
0,0 \\
-9999\end{array}$ \\
\hline$\frac{\pi}{\frac{\pi}{\pi}}$ & $\begin{array}{c}0,3 \\
6,3 \\
19,0 \\
38,1\end{array}$ & $\begin{array}{l}0,9 \\
0,7 \\
0,3 \\
0,0\end{array}$ & $\begin{array}{c}0,9 \\
0,7 \\
0,1 \\
-9999\end{array}$ & $\begin{array}{c}0,9 \\
0,4 \\
0,0 \\
-9999\end{array}$ & $\begin{array}{c}1,0 \\
0,4 \\
0,0 \\
-9999\end{array}$ & $\begin{array}{c}0,9 \\
0,5 \\
0,1 \\
0,000\end{array}$ \\
\hline 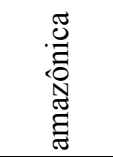 & $\begin{array}{c}0,3 \\
6,3 \\
19,0 \\
38,1\end{array}$ & $\begin{array}{c}1,0 \\
0,7 \\
0,1 \\
0,000\end{array}$ & $\begin{array}{c}1,0 \\
0,4 \\
0,1 \\
-9999\end{array}$ & $\begin{array}{c}1,0 \\
0,4 \\
0,1 \\
-9999\end{array}$ & $\begin{array}{c}0,9 \\
0,5 \\
0,0 \\
-9999\end{array}$ & $\begin{array}{c}1,0 \\
0,7 \\
0,1 \\
-9999\end{array}$ \\
\hline \multicolumn{7}{|c|}{ SEM1 } \\
\hline . & $\begin{array}{c}0,3 \\
6,3 \\
19,0 \\
38,1\end{array}$ & $\begin{array}{c}0,7 \\
0,6 \\
0,5 \\
-9999\end{array}$ & $\begin{array}{c}0,6 \\
0,5 \\
0,1 \\
-9999\end{array}$ & $\begin{array}{c}0,7 \\
0,5 \\
0,0 \\
-9999\end{array}$ & $\begin{array}{c}0,6 \\
0,5 \\
0,1 \\
-9999\end{array}$ & $\begin{array}{c}0,5 \\
0,2 \\
0,0 \\
-9999\end{array}$ \\
\hline$\frac{\pi}{\frac{\pi}{0}}$ & $\begin{array}{c}0,3 \\
6,3 \\
19,0 \\
38,1\end{array}$ & $\begin{array}{l}0,9 \\
0,7 \\
0,4 \\
0,0\end{array}$ & $\begin{array}{c}0,9 \\
0,7 \\
0,1 \\
-9999\end{array}$ & $\begin{array}{c}0,9 \\
0,4 \\
0,0 \\
-9999\end{array}$ & $\begin{array}{c}1,0 \\
0,4 \\
0,0 \\
-9999\end{array}$ & $\begin{array}{l}0,9 \\
0,5 \\
0,2 \\
0,0\end{array}$ \\
\hline 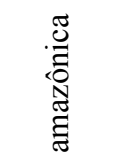 & $\begin{array}{c}0,3 \\
6,3 \\
19,0 \\
38,1\end{array}$ & $\begin{array}{l}1,0 \\
0,7 \\
0,1 \\
0,0\end{array}$ & $\begin{array}{c}1,0 \\
0,5 \\
0,1 \\
-9999\end{array}$ & $\begin{array}{c}1,0 \\
0,5 \\
0,1 \\
-9999\end{array}$ & $\begin{array}{c}0,9 \\
0,5 \\
0,0 \\
-9999\end{array}$ & $\begin{array}{c}1,0 \\
0,7 \\
0,1 \\
-9999\end{array}$ \\
\hline \multicolumn{7}{|c|}{ DIA025 } \\
\hline 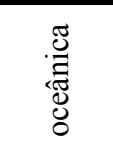 & $\begin{array}{c}0,3 \\
6,3 \\
19,0 \\
38,1\end{array}$ & $\begin{array}{c}0,6 \\
0,6 \\
0,5 \\
-9999\end{array}$ & $\begin{array}{c}0,6 \\
0,4 \\
0,1 \\
-9999\end{array}$ & $\begin{array}{c}0,7 \\
0,5 \\
0,0 \\
-9999\end{array}$ & $\begin{array}{c}0,6 \\
0,5 \\
0,0 \\
-9999\end{array}$ & $\begin{array}{c}0,5 \\
0,2 \\
0,0 \\
-9999\end{array}$ \\
\hline$\frac{\pi}{\frac{\pi}{2}}$ & $\begin{array}{c}0,3 \\
6,3 \\
19,0 \\
38,1\end{array}$ & $\begin{array}{l}0,9 \\
0,7 \\
0,3 \\
0,0\end{array}$ & $\begin{array}{c}0,9 \\
0,7 \\
0,1 \\
-9999\end{array}$ & $\begin{array}{c}0,9 \\
0,4 \\
0,0 \\
-9999\end{array}$ & $\begin{array}{c}1,0 \\
0,4 \\
0,0 \\
-9999\end{array}$ & $\begin{array}{l}0,9 \\
0,5 \\
0,1 \\
0,0\end{array}$ \\
\hline 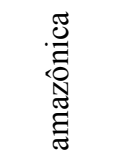 & $\begin{array}{c}0,3 \\
6,3 \\
19,0 \\
38,1\end{array}$ & $\begin{array}{l}0,9 \\
0,7 \\
0,1 \\
0,0\end{array}$ & $\begin{array}{c}1,0 \\
0,4 \\
0,1 \\
-9999\end{array}$ & $\begin{array}{c}1,0 \\
0,5 \\
0,1 \\
-9999\end{array}$ & $\begin{array}{c}0,9 \\
0,5 \\
0,0 \\
-9999\end{array}$ & $\begin{array}{c}1,0 \\
0,8 \\
0,1 \\
-9999\end{array}$ \\
\hline
\end{tabular}


de chuva-não chuva $\left(0,3 \mathrm{~mm} \mathrm{dia}^{-1}\right)$, decrescendo gradativamente para os limiares subsequentes. Desta forma, o modelo BRAMS possui desempenho superior em prever a ocorrência/não ocorrência de chuva do que em localizar os núcleos mais intensos. Mendonça (1999), por exemplo, obteve conclusão similar para o modelo global CPTEC/COLA.

O desempenho do modelo foi inferior para a simulação de precipitação na região de ZCAS oceânica e superior para a amazônica, na qual os valores de TSA são iguais ou próximos de 1, principalmente para o limiar mais baixo de chuva. $\mathrm{Na}$ região costeira, o modelo apresenta desempenho intermediário com relação às outras duas regiões para este mesmo limiar. Resultados para o evento ZCAS-99 não serão apresentados, pois são semelhantes aos obtidos para ZCAS-98.

\section{CONCLUSÕES}

Foram realizadas simulações numéricas com o modelo BRAMS para dois eventos de ZCAS com três diferentes condições iniciais e de fronteira de TSM. Exploraram-se aspectos relativos à influência das resoluções espacial e temporal desses dados na simulação da precipitação associada à ZCAS. Além disso, foi realizada uma análise baseada em índices estatísticos, a fim de verificar o desempenho do modelo numérico em simular a precipitação associada à ZCAS nas três regiões que a compõem (oceânica, costeira e amazônica).

O experimento que utilizou dados de TSM semanal com resolução espacial de $1^{\circ} \times 1^{\circ}$ (SEM1) foi o experimento com maior quantidade de precipitação e fluxo de calor latente mais intenso na superfície oceânica. Neste experimento a TSM média é superior à dos demais experimentos, induzindo maior evaporação e aquecimento em baixos níveis, favorecendo, portanto, o desenvolvimento de precipitação. O experimento com menor quantidade de precipitação acumulada na ZCAS oceânica foi o que utilizou TSM diária com resolução espacial de $0,25^{\circ} \times 0,25^{\circ}$ (DIA025), seguido do experimento que utilizou TSM semanal com mesma resolução espacial (SEM025) e de SEM1, nesta ordem.

Obteve-se que o viés do modelo é dependente do limiar de chuva e que o modelo erra de forma sistemática para limiares mais altos de precipitação. O modelo BRAMS superestima a precipitação para limiares mais baixos e subestima para os mais altos, sendo melhor em identificar a ocorrência/não ocorrência de chuva do que em localizar os núcleos de chuva mais intensos.

O modelo apresentou destreza levemente superior (inferior) na simulação de precipitação associada aos eventos de ZCAS estudados com o uso de dados de TSM com resoluções espacial e temporal mais refinadas (grosseiras), entretanto essas diferenças no desempenho do modelo foram pouco significativas. Com relação às regiões que compõem a ZCAS, o desempenho do modelo na localização da precipitação foi superior para a amazônica e inferior para a oceânica. Não foram observadas diferenças significativas entre os resultados obtidos para os eventos de ZCAS ocorridos em distintas fases do ENOS (ZCAS-98 e ZCAS-99). Deve-se salientar que a análise estatística foi realizada com apenas dois casos, necessitando de um estudo mais amplo para obter resultados mais robustos.

Desta forma, sugere-se que a resolução espaço-temporal dos dados de TSM influencia de forma pouco significativa na representação da ZCAS pelo modelo BRAMS, tanto para eventos ocorridos durante o El Niño, quando a ZCAS é mais oceânica, quanto para os ocorridos durante a La Niña, quando a ZCAS é mais continental.

\section{AGRADECIMENTOS}

Ao Dr. Pedro Leite da Silva Dias (IAG-USP) pelas sugestões de grande valia. Ao Dr. Dirceu Luis Herdies (CPTEC/ INPE) pelas sugestões e concessão dos dados das reanálises. A primeira autora agradece à Fundação de Amparo à Pesquisa do Estado de São Paulo (FAPESP) (processo n ${ }^{\circ} .2007 / 57101-2$ ) e ao Conselho Nacional de Desenvolvimento Científico e Tecnológico (CNPq) pelo apoio financeiro. Os autores também gostariam de agradecer pelas contribuições dos revisores anônimos e à CAPES/PROEX pelo auxílio-publicação.

\section{REFERÊNCIAS BIBLIOGRÁFICAS}

BALDWIN, M. E.; KAIN, J. S. Sensitivity of several performance measures to displacement error, bias, and event frequency. Weather and Forecasting, v. 21, p. 636-648, ago. 2006.

BARREIRO, M.; CHANG, P.; SARAVANAN, R. Variability of the South Atlantic Convergence Zone simulated by an Atmospheric General Circulation Model. Journal of Climate, v. 15, p. 745-763, abr. 2002.

BARROS, V. et al. Influence of the South Atlantic Convergence Zone and South Atlantic sea surface temperature on interannual summer rainfall variability in Southeastern South America. Theoretical and Applied Climatology, v. 67, p. 123-133, 2000.

CALDERON, D. Influência da temperatura da superfície do mar e da convecção em simulações regionais para a Zona de Convergência do Atlântico Sul. 2000. 89 f. Dissertação (Mestrado em Meteorologia) - Instituto de Astronomia, Geofísica e Ciências Atmosféricas, Universidade de São Paulo, São Paulo, 2000.

CARVALHO, L. M. V.; JONES, C. Zona de Convergência do Atlântico Sul. In Tempo e Clima no Brasil. Cavalcanti. I. 
F. A.; Ferreira, N. J.; Silva, M. G. A. J.; Silva Dias, M. A. F. (org.). São Paulo: Oficina de Textos, 2009; p. 95-109.

CARVALHO, L. M. V.; JONES, C.; LIEBMANN, B. The South Atlantic Convergence Zone: intensity, form, persistence, and relationships with intraseasonal to interannual activity and extreme rainfall. Journal of Climate, v. 17, p. 88-108, 2004.

CASARIN, D. P.; KOUSKY, V. E. Anomalias de precipitação no sul do Brasil e variações na circulação atmosférica. Revista Brasileira de Meteorologia, v. 1, p. 83-90, 1986.

CHAVES, R. R.; NOBRE, P. Interaction between sea surface temperature over the South Atlantic Ocean and the South Atlantic Convergence Zone. Geophysical Research Letters, v. 31, L03204, fev. 2004.

CHAVES, R. R.; SATYAMURTY, P. Estudo das condições regionais associadas a um evento de forte ZCAS em janeiro de 2003. Revista Brasileira de Meteorologia, v. 21, n. 1, p. 134-140, abr. 2006.

CHEN, C; COTTON, W. R. A one-dimensional simulation of the Stratocumulus-capped mixed layer. Boundary-Layer Meteorology, v. 25, n. 3, p. 289-321, mar. 1983.

COTTON, W. R. et al. RAMS 2001: Current status and future directions. Meteorology and Atmospheric Physics, v. 82, n. 1-4, p. 5-29, jan. 2003.

FERREIRA, N. J.; SANCHES, M.; SILVA DIAS, M. A. F. Composição da Zona de Convergência do Atlântico Sul em períodos de El Niño e La Niña. Revista Brasileira de Meteorologia, v. 19, n. 1, p. 89-98, jun. 2004.

GRELL, G. A. Prognostic evaluation of assumptions used by Cumulus parameterizations. Monthly Weather Review, v.121, p. 764-787, mar. 1993.

HUFFMAN, G. J. et al. Global precipitation at one-degree daily resolution from multisatellite observations. Journal of Hydrometeorology, v. 2, p. 36-50, fev. 2001.

JOYCE, R. J.; ARKIN, P. A. Improved estimates of tropical and subtropical precipitation using the GOES precipitation index. Journal of Atmospheric and Oceanic Technology, v. 14, p. 997-1011, out. 1997.

JORGETTI, T. A Zona de Convergência do Atlântico Sul e os processos oceânicos do Atlântico e do Pacífico. 2008. 169 f. Tese (Doutorado em Meteorologia) - Instituto de Astronomia, Geofísica e Ciências Atmosféricas, Universidade de São Paulo, São Paulo, 2008.

KODAMA, Y. Large-scale common features of subtropical precipitation zones (the Baiu Frontal Zone, the SPCZ, and the SACZ). Part I: Characteristics of the subtropical frontal zones. Journal of the Meteorological Society of Japan, v. 70, n. 4, p. 813-836, ago. 1992.

KODAMA, Y. Large-scale common features of sub-tropical convergence zones (the Baiu Frontal Zone, the SPCZ, and the SACZ). Part II: Conditions of the circulations for generating the STCZs. Journal of the Meteorological Society of Japan, v. 71, n. 5, p. 581-610, out. 1993.

LIEBMANN, B.; JONES, C.; CARVALHO, L. M. V. Interannual variability of daily extreme precipitation events in the State of São Paulo, Brazil. Journal of Climate, v. 14, p. 208-218, jan. 2001.

LIMA, K. C. Episódios de precipitação intensa no sudeste do Brasil e a influência das anomalias de temperatura da superfície do mar e da topografia. 2010. 229 f. Tese (Doutorado em Meteorologia) - Instituto Nacional de Pesquisas Espaciais, São José dos Campos, 2010.

LIMA, K. C.; SATYAMURTY, P. Large-scale atmospheric conditions associated with heavy rainfall episodes in Southeast Brazil. Theoretical and Applied Climatology, v. 101, p. 121-135, 2010.

MENDONÇA, A. M. Desempenho do modelo global CPTEC/ COLA durante episódios de ZCAS, utilizando os esquemas de convecção profunda tipo Kuo e ArakawaSchubert relaxada. 1999. 166 f. Dissertação (Mestrado em Meteorologia) - Instituto Nacional de Pesquisas Espaciais, São José dos Campos, 1999.

NOBRE, P. et al. Modulações da ZCAS pelas temperaturas da superfície do mar no Atlântico Sudoeste. In: CONGRESSO BRASILEIRO DE METEOROLOGIA, 12., 2002, Foz do Iguaçu. Anais... Rio de Janeiro: Sociedade Brasileira de Meteorologia, 2002.

NINOMIYA, K. Similarity and difference between the South Atlantic Convergence Zone and the Baiu Frontal Zone simulated by an AGCM. Journal of the Meteorological Society of Japan, v. 85, n. 3, p. 277-299, jun. 2007.

PIELKE, R. A. et al. A comprehensive meteorological modeling system - RAMS. Meteorology and Atmospheric Physics, v. 49, p. 69-91, 1992.

PIELKE, R. A. Mesoscale Meteorological Modeling. 2. ed. Londres: Academic Press, 2002, 676 p.

QUADRO, M. F. L. Estudo de episódios de Zona de Convergência do Atlântico Sul (ZCAS) sobre a América do Sul. 1994. 89f. Dissertação (Mestrado em Meteorologia) - Instituto Nacional de Pesquisas Espaciais, São José dos Campos, 1994.

REYNOLDS, R. W. et al. An improved in situ and satellite SST analysis for climate. Journal of Climate, v. 15, p. 16091625, jul. 2002.

REYNOLDS, R. W. et al. Daily high-resolution-blended analyses for sea surface temperature. Journal of Climate, v. 20, p. 5473-5496, nov. 2007.

SACRAMENTO NETO, O. B.; ESCOBAR, G. C. J.; SILVA, P. E. D. Método objetivo para identificar episódios de Zonas de Convergência de Umidade (ZCOU) no ambiente operacional do Centro de Previsão de Tempo e Estudos Climáticos - CPTEC. In: CONGRESSO BRASILEIRO 
DE METEOROLOGIA, 16., 2010, Belém. Anais... Rio de Janeiro: Sociedade Brasileira de Meteorologia, 2010.

TREMBACK, C. J. Numerical simulation of a Mesoscale Convective Complex: model development and numerical results. 1990. $247 \mathrm{f}$. Tese (Doutorado) - Department of Atmospheric Science, Colorado State University, Fort Collins, 1990.

TRIPOLI, G. J.; COTTON, W. R. The Colorado State University three-dimensional cloud/mesoscale model - 1982, Part I: General theoretical framework and sensitivity experiments. Journal de Recherches Atmospheriques, v. 16, p. 185220, 1982.
UPPALA, S. M. et al. The ERA-40 re-analysis. Quarterly Journal of the Royal Meteorological Society, v. 131, $\mathrm{n}$. 612, p. 2961-3012, out. 2005.

WALKO, R. L. et al. New RAMS cloud microphysics parameterization. Part I: The single-moment scheme. Atmospheric Research, v. 38, p. 29-62, 1995.

WALKO, R. L. et al. Coupled atmosphere-biophysics-hydrology models for environmental modeling. Journal of Applied Meteorology and Climatology, v. 39, p. 931-944, jun. 2000. WILKS, D. S. Statistical Methods in the Atmospheric Sciences. 2. ed. Burlington: Academic Press, 2006, 627 p. 